\title{
What Are They Talking About? Depth of Engineering Student Sociotechnical Thinking in a Technical Engineering Course
}

\section{Dr. Natasha Andrade, University of Maryland, College Park}

Dr. Natasha Andrade is a Lecturer in the Civil and Environmental Engineering Department at the University of Maryland College Park. Her responsibilities include teaching various undergraduate courses in environmental engineering (such as Engineering for Sustainability and Environmental Engineering Science) and conducting engineering education research. She has specialized in redesigning engineering courses to make them learner-centered and based on active learning activities. More recently, she started work on engineering education research that aims to effectively incorporate socio-technical thinking in required technical courses. Her discipline research is focused on the production of stabilized biosolids, its use as a fertilizer and its impact on environmental pollution concerning organic contaminants. She recently has started work on Amazonic mercury contamination due to illegal mining.

\section{Dr. David Tomblin, University of Maryland, College Park}

David is the director of the Science, Technology and Society program at the University of Maryland, College Park. He works with STEM majors on the ethical and social dimensions of science and technology. David also does public engagement with science and technology work with government agencies such as NASA, DOE, and NOAA. 
What are they talking about? Depth of engineering student socio-technical thinking in a technical engineering course

Dr. Natasha Andrade, University of Maryland

Dr. David Tomblin, University of Maryland

\begin{abstract}
In the last decade, there have been several efforts from engineering faculty to include social justice and socio-technical thinking in the engineering curriculum. For example, Leydens and Lucena report several examples of courses at different universities that aim to make social justice more visible in the engineering curriculum ${ }^{1}$. Creating new courses and adding modules to existing ones can be extremely valuable interventions. However, making socio-technical thinking an integral part of existing technical courses is also a necessary approach to reduce the perception that "social" issues are not equally valued in the engineering ${ }^{1,2}$. The efficacy of such efforts has not been widely tested.

This paper builds on our analysis of an effort to incorporate socio-technical systems thinking into a required civil and environmental engineering sophomore level course to test whether such interventions effectively bridge the socio-technical divide in engineering curriculum ${ }^{3}$. Our previous study found that class activities spurred more reflection on social factors that influence technological development, increased awareness of stakeholder diversity, and encouraged appreciation of socio-technical system complexity. While the initial analysis detected an increased level of second-order socio-technical thinking, it didn't systematically consider the specific socio-political content of student responses to the activities. Our current analysis employs open coding of student work to evaluate if, when, and how students are able to transcend instrumental socio-technical systems thinking about technology, which narrowly defines social relationships with technology in terms of first-order efficiency and productivity outcomes ${ }^{4,5}$. These sorts of outcomes are perceived as value-free and depoliticized, thus rhetoric that comfortably fits into the practice of engineering ${ }^{6}$.
\end{abstract}

\title{
Introduction
}

It is recognized by a strong body of researchers, scholars, and professors, that the incorporation of macro-ethics and socio-technical thinking in the engineering curriculum is important and challenging ${ }^{7-12}$. In the last decade, there have been several efforts from engineering faculty to include social justice and socio-technical thinking in the engineering curriculum. For example, Leydens and Lucena report several examples of courses at different universities that aim to make social justice more visible in the engineering curriculum ${ }^{1}$. Larger efforts are also reported, for example, a University of San Diego faculty group developed courses and modules that bring more importance to socio-technical aspects of engineering education and practice ${ }^{13}$. Creating new courses and adding modules to existing ones can be extremely valuable interventions ${ }^{14}$. However, making socio-technical thinking an integral part of existing technical courses is also a necessary approach to reduce the perception that "social" issues are not equally valued in engineering ${ }^{1,2}$.

In the last two years, the authors have strategically integrated socio-technical thinking into a required civil and environmental engineering sophomore-level technical course ${ }^{3}$. In the context of this course, socio-technical thinking considers that technology evolves within a social and cultural context and is shaped by this context ${ }^{15}$. When the effort to include socio-technical 
activities in this course started, there were two classroom activities integrated in the course; now, socio-technical thinking is present in most of the activities and is discussed for all technologies covered by the course content. Our previous study ${ }^{3}$ found that class activities spurred more reflection on social factors that influence technological development, increased awareness of stakeholder diversity, and encouraged appreciation of socio-technical system complexity. While the initial analysis detected an increased level of second-order socio-technical thinking, it did not systematically consider the specific socio-political content of student responses to the activities. Before we present the results of this study, we outline factors that create challenges for students attempting to integrate socio-technical thinking into their analysis of emerging technologies.

Engineers, just as any other professional group, work under a framework of cultural values that generate an engineer identity ${ }^{6}$. This engineer identity is generally reinforced over the career of engineers, particularly during undergraduate education ${ }^{16,17}$ and the first few years of practice. There are several mindsets that inform this engineer identity, for example, meritocracy, centrality of military and corporate organizations, uncritical acceptance of authority, technical narrowness, willingness to help, instrumentalism, among others ${ }^{1,4-6,18}$. In our analysis, we focus on one aspect of this engineering culture: instrumental thinking. Instrumental thinking is a narrow view of how humans impact technology and how technology can impact humans. This narrow view assumes that engineers think of technology and technological artifacts as value-free, that technology itself cannot be considered bad or good, technology only acquires values when humans use it ${ }^{1,4,19}$. Instrumentalism is also reflected in a first-order socio-technical thinking, in which social relationships with technology are defined in terms of efficiency and productivity outcomes ${ }^{3,5,20}$. These sorts of outcomes are perceived as value-free and depoliticized, thus rhetoric that comfortably fits into the practice of engineering ${ }^{6}$.

It is easy to adhere to the idea that an engineer would not choose to design a technology with the intent to generate a negative outcome. After all, many of the engineering professional society ethics canons (if not all) mention that engineers should "hold paramount the safety, health and welfare of the public ${ }^{21}$. The Accreditation Board for Engineering and Technology has in its definition of engineering that engineering is work "...for the benefit of humankind" 4 . So, if engineers have a true desire to work for the benefit of humankind and have a willingness to help others ${ }^{1,18}$, how could the technology they design be bad?

For students of engineering, understanding the underlying values of a technology can be challenging. Instrumental thinking, along with the sources of this mindset, can be hidden to engineering students because it is so ingrained in the engineer identity of the students that it may be hard to recognize as a cultural bias. Some of the hidden sources of instrumental thinking may be of an individual nature, while others may be of a broader socio-structural nature. On an individual level, engineers may be what Newberry calls proximate instrumentalists ${ }^{4}$. Engineers may behave as instrumentalists towards technologies they are experts in and as noninstrumentalists towards technologies they are unfamiliar with or have no expertise in. For example, a civil engineer could probably see ethical and social issues with human gene-altering technologies but would take a myopic view if asked to discuss the social influence and impact of bridge design.

On a broader societal level, instrumentalism can be present in education, both in K-12 education as well as higher education classrooms and culture. Several studies have demonstrated that K-12 science curriculum reproduces the social/technical divide, creating a culture of instrumentalism well before students reach college ${ }^{22-24}$. Perhaps the exception to this rule are the rare students that have the opportunity to go through high school engineering programs such as 
Project Lead the Way, which focus on an engaging, hands-on design curriculum. However, such programs can be seen as a "bait and switch," as they contrast sharply with the narrow technical and theoretical focus of traditional college engineering curriculum ${ }^{25}$. Nonetheless, it has been noted that many matriculating 1st year engineering students arrive on campus with an instrumental mindset ${ }^{26}$. At the college level, engineering professors often reinforce instrumentalism when they design lectures and classroom activities that focus solely on technical and fundamental theoretical knowledge ${ }^{27,28}$. In engineering classes, the distance between the technical aspects of a technology and its social impacts can be so great that engineering students feel that des31ign constraints imposed during the design process of a certain technology are simply based on technical constraints and unrelated to the social fabric in which the technology exists or will exist in ${ }^{5,10-12}$. In an even broader context, engineering has a culture of militarism and a focus on industries and companies. Defense contractors that work with the government seem to be the largest employers of engineers and a large amount of research funds are poured into engineering and defense related projects ${ }^{18}$. Militarism is also deeply entrenched in engineering education, making a strong presence in classroom culture (rigidity of assignment deadlines, marginalization of women, extremely intense time-constrained exams, etc.) and in engineering education content in the form of military examples in textbooks for example ${ }^{18,29}$. More importantly to our point, this military culture can manifest in students emotionally distancing themselves from the technology they create, which removes value from and depoliticizes the technology itself ${ }^{30}$.

Our study employs open coding of student responses to a week-long series of activities that invite students to think about electric and autonomous vehicle integration into existing socio-technical infrastructure. This study aims to answer the following two research questions related to the extent students transcend instrumental socio-technical systems thinking about technology. Our questions are:

1) What are the common ways that students construct social, political, and economic issues related to autonomous/electric vehicles?

2) Based on previous work ${ }^{3}$, it was established that the classroom activities encourage socio-technical systems thinking. What are the instrumental and noninstrumental constructs that students use to inform their articulation of sociotechnical systems?

To answer these questions, we use the definition of instrumental thinking provided above along with its root sources. When students are successful at breaking from this type of thinking, we consider that they are able to achieve second-order thinking, defined as identifying and establishing indirect connections and consequences beyond direct cause and effect relationships of technologies and technological artifacts ${ }^{20}$ and thinking about the social consequences of technology beyond productivity and efficiency ${ }^{31}$.

\section{Methods}

Participants and Context

Students enrolled in the Engineering for Sustainability course were the target of this research project. Here, we will discuss data generated by a total of 60 students that were enrolled during the Spring 2018 semester (students were coded as Student 51 to Student 110) . All 60 students' work was theme-coded per the methods outlined in Andrade and Tomblin ${ }^{3}$. For the open-coding analysis of student social statements, we coded a subsample of 32 of these students. 


\section{Classroom Activity - Electric and Autonomous Vehicle Systems}

The Electric and Autonomous Vehicle Systems activity (hereafter referred to as the EV/AV activity) consists of two in-class days with several pre and post assessments that are conducted in class, online, with student groups, and individual students. The EV/AV activity is fully described in previously published work ${ }^{3}$. In brief, students are given a reading assignment ${ }^{15}$ before they come to class. They are also asked individual questions that they answer online. The questions asked were slightly modified from the previous work ${ }^{3}$ and can be seen on Table 1 . On the first day of the activity, the instructors lead a discussion and then students are grouped. They read five articles about Electric Vehicle (EV) adoption ${ }^{32-36}$ and participate in a studentcentered activity. After class, the students answer individual questions online that reflect their classroom discussions (Table 1). Before the second day of the activity, students individually answer a set of questions online. In class, on the second day, students are briefly introduced to autonomous vehicles (AVs) and the status of the technology. Then they are grouped, read a couple of articles ${ }^{37,38}$, and then work on a set of questions that are based on a specific EV/AV adoption scenario. The set of questions that students answer as a group prompt them to think about how certain stakeholders would impact and would be impacted by EV/AVs. This becomes very relevant in our discussion of the results. The stakeholders that students are asked to consider are: middle-income family, real estate industry, and urban planners. After class, students answer questions individually online that require them to reflect on the classroom discussions (Table 1).

\section{Analysis}

In this paper, we report the analysis of one of the questions asked during the EV/AV activity. The question chosen for this analysis is named below as After Day 2, bolded in Table 1. All questions assigned for this activity are graded, but only on the basis of completion. Students weren't constrained by a rubric that would imply a right or wrong way to answer the questions. The question that was chosen is the final question students answered after all activities were completed and generally represent the culminating student thoughts about this socio-technical intervention. This question also contains the highest frequency of social references. The students' data was coded with thematic coding ${ }^{39}$ and with open coding ${ }^{40}$. We used the same coding themes as in the previous study (environmental, economic, social, political/power, infrastructure, technology, complexity, uncertainty) ${ }^{3}$, while the open coding was used to analyze more specifically the kinds of social, political, and economic statements most salient with students. Both authors coded the student work separately and compared notes to establish seven categories of social statements that students frequently used. 
Table 1 - Questions posed to the students before and after the EV/AV classroom activities. The After Day 2 class question was coded through thematic and open coding. Table also shows how the authors will refer to the questions henceforth (question code).

\begin{tabular}{|l|l|l|}
\hline Activity Timing & Question Code & Question Asked \\
\hline Pre $1^{\text {st }}$ class quiz & $\begin{array}{l}\text { Before Day 1 - initial } \\
\text { perceptions of electric vehicles }\end{array}$ & $\begin{array}{l}\text { [Next class] we will discuss electric } \\
\text { vehicles adoption. How do you think } \\
\text { electric vehicles will shape people's lives } \\
\text { and how will people shape the } \\
\text { development of electric vehicles? Please } \\
\text { answer the questions in a 150-word } \\
\text { paragraph. }\end{array}$ \\
\hline Quiz after $1^{\text {st }}$ class & $\begin{array}{l}\text { After Day 1 - social impact of } \\
\text { electric vehicles }\end{array}$ & $\begin{array}{l}\text { How do you think electric vehicles will } \\
\text { shape people's lives and how will people } \\
\text { shape the development of electric } \\
\text { vehicles? Please answer the questions in a } \\
\text { 150-word paragraph. }\end{array}$ \\
\hline Pre $2^{\text {nd }}$ class quiz & $\begin{array}{l}\text { Before Day 2 - initial } \\
\text { perceptions of driverless }\end{array}$ & $\begin{array}{l}\text { [Next class] we will discuss driverless } \\
\text { vehicles adoption. How do you think } \\
\text { driverless vehicles will shape people's } \\
\text { lives and how will people shape the } \\
\text { development of driverless vehicles? Please } \\
\text { answer the questions in a 150-word } \\
\text { paragraph. }\end{array}$ \\
\hline $\begin{array}{l}\text { Quiz after } 2^{\text {nd }} \\
\text { class }\end{array}$ & $\begin{array}{l}\text { After Day 2 - social impact of } \\
\text { driverless vehicles }\end{array}$ & $\begin{array}{l}\text { How do you think driverless } \\
\text { vehicles (and the infrastructure changes } \\
\text { that accompany it) will shape people's } \\
\text { lives and how will people shape the } \\
\text { development of driverless vehicles? } \\
\text { Please answer the questions in a 150- } \\
\text { word paragraph. }\end{array}$ \\
\hline
\end{tabular}

\section{Findings and Discussion}

Results

Thematic coding of the culminating question (After Day 2) of the EV/AV activity in Spring 2018 resulted in social and political remarks constituting $46.2 \%$ of the content of student answers (Table 2). Despite the different framing of the culminating question in Fall 2017, which was changed in Spring 2018 as a pedagogical refinement of the activity, we see a similar result ( social + political $=40.1 \%$ in Fall 2017). Our previous work, where we analyzed student preconceptions of socio-political aspects of EV/AV adoption strongly suggests that the activities in class encourage students to think more about the social and political relationships between technology and society ${ }^{3}$. Since we see here similar results as obtained before, this suggests that these activities consistently have this impact in students' thinking processes. It is relevant to note that, while we did see previously that the activities have a significant impact in students' 
responses, the activities may not be the sole justification for the differences in responses as students have several other life situations that may be influencing them during the semester in which these activities take place.

Table 2 - Percentage of student references for each coding theme for answers to the final questions at the end of the EV/AV activity in Fall 2017 ( $n=50$ student responses $)$ and Spring 2018 ( $\mathrm{n}=60$ student responses).

\begin{tabular}{|l|c|c|c|c|}
\hline \multicolumn{1}{|c|}{ Code Theme } & $\begin{array}{c}\text { Count (Fall } \\
\text { 2017) }\end{array}$ & $\begin{array}{c}\text { Question: After } \\
\text { Day 2(\%): } \\
\text { Driverless } \\
\text { vehicle } \\
\text { community } \\
\text { well-being (Fall } \\
\text { 2017) }\end{array}$ & $\begin{array}{c}\text { Count (Spring } \\
\text { 2018) }\end{array}$ & $\begin{array}{c}\text { Question: After } \\
\text { Day 2 (\%): } \\
\text { Social Impact of } \\
\text { Driverless } \\
\text { Vehicles } \\
\text { (Spring 2018) }\end{array}$ \\
\hline Environmental & 22 & $6.8 \%$ & 13 & $3.2 \%$ \\
\hline Economic & 55 & $17.1 \%$ & 34 & $8.4 \%$ \\
\hline Social & 101 & $31.4 \%$ & 151 & $37.1 \%$ \\
\hline Political/Power & 28 & $8.7 \%$ & 37 & $9.1 \%$ \\
\hline Complexity & 20 & $6.2 \%$ & 26 & $8.4 \%$ \\
\hline Uncertainty & 12 & $3.7 \%$ & 36 & $12.3 \%$ \\
\hline Infrastructure & 52 & $16.2 \%$ & 50 & $14.7 \%$ \\
\hline Technology & 32 & $9.9 \%$ & 60 & $100 \%$ \\
\hline Total & 322 & $100 \%$ & 402 & \\
\hline
\end{tabular}

Research Question 1: What are the common ways that students construct social, political, and economic issues related to autonomous/electric vehicles?

Open coding of student social, political, and economic references identified seven major (common) themes (Table 3) and nine minor (less common) themes (See Appendix). In this paper we focus on the major themes, but briefly report the minor themes to illustrate the diversity of ways students were thinking about the social, political, and economic aspects of autonomous vehicles. $^{1}$

\footnotetext{
${ }^{1}$ This study focuses on the diversity of ways students articulate social references, therefore we don't provide frequency data here. Major versus minor themes are determined by relative commonality, though. Future studies will recode the data using the major and minor themes established here to determine frequency of student references that fall into each theme and to determine whether these themes are consistent across semesters.
} 
Table 3 - Major themes of student social, political, and economic references. Whether a theme has predominantly instrumental, non-instrumental, or mixed references is also noted below.

\begin{tabular}{|c|c|c|}
\hline Major Theme & Explanation & Student Example \\
\hline $\begin{array}{l}\text { Strained Social } \\
\text { Relationships } \\
\text { (non-Instrumental) }\end{array}$ & $\begin{array}{l}\text { Social interactions among people that } \\
\text { would lead to potential negative } \\
\text { changes in social relationships among } \\
\text { family members, friends, and } \\
\text { community members. }\end{array}$ & $\begin{array}{l}\text { Student 53: "For a family in which parents work and } \\
\text { a child attends school and participates in other } \\
\text { activities, driverless vehicles could allow the parents } \\
\text { to work as late as needed, while also getting their } \\
\text { child to their activity on time. Although this may be } \\
\text { convenient, the relationship between child and parent } \\
\text { would be strained, as they would not have to spend } \\
\text { car rides together, nor would the parents be attending } \\
\text { their child's activity." }\end{array}$ \\
\hline $\begin{array}{l}\text { Quality of Life } \\
\text { (non-Instrumental) }\end{array}$ & $\begin{array}{l}\text { Improvement of human lives that go } \\
\text { beyond technological impacts on human } \\
\text { productivity, convenience, and } \\
\text { efficiency. Quality of life statements } \\
\text { include, for example, notions of bodily } \\
\text { health and integrity, free thought, } \\
\text { emotional well-being, a sense of } \\
\text { belonging, play, and political freedom. }\end{array}$ & $\begin{array}{l}\text { Student 100: "Furthermore, there will be much less } \\
\text { need for parking in cities with allow for increased } \\
\text { greenery and bike lanes making it much more } \\
\text { pleasant to live in a city." }\end{array}$ \\
\hline $\begin{array}{l}\text { Infrastructure } \\
\text { Design (Mix) }\end{array}$ & $\begin{array}{l}\text { Referring to how the adoption of } \\
\text { electric and autonomous vehicles will } \\
\text { necessitate changes in infrastructure and } \\
\text { how those changes will affect people. }\end{array}$ & $\begin{array}{l}\text { Student 101: "The infrastructure will become } \\
\text { affected depending on how the vehicles are used. If it } \\
\text { is more ride-sharing, there will be less parking } \\
\text { spaces needed. Also, whole entire roadway } \\
\text { infrastructure will need to be changed. For example, } \\
\text { the traffic patterns, street signs, sidewalks, etc. .." }\end{array}$ \\
\hline $\begin{array}{l}\text { Public Acceptance } \\
\text { (Instrumental) }\end{array}$ & $\begin{array}{l}\text { Referring to the need of the public to } \\
\text { accept, demand, and adjust to emerging } \\
\text { technology in order for it to be } \\
\text { successful. These statements also } \\
\text { include projections of public desire for } \\
\text { instrumental technical and economic } \\
\text { attributes such as safety, reliability, and } \\
\text { convenience. }\end{array}$ & $\begin{array}{l}\text { Student 75: "As soon as people feel safe in these } \\
\text { cars and feel as though riding in these cars is more } \\
\text { effective than driving themselves everywhere they } \\
\text { will use them more." }\end{array}$ \\
\hline $\begin{array}{l}\text { Human Error } \\
\text { (Instrumental) }\end{array}$ & $\begin{array}{l}\text { Emphasizes the role of technology in } \\
\text { reducing human error. Statements often } \\
\text { socially construct the human driver as } \\
\text { other, an unempathetic stereotype, in } \\
\text { negative terms. }\end{array}$ & $\begin{array}{l}\text { Student 79: "Driverless cars will eliminate the } \\
\text { human emotion factor in driving on the road and } \\
\text { ultimately protect people from getting into } \\
\text { accidents." }\end{array}$ \\
\hline $\begin{array}{l}\text { Economic } \\
\text { Efficiency } \\
\text { (Instrumental) }\end{array}$ & $\begin{array}{l}\text { Uncritically emphasizes simple models } \\
\text { of technological impact that relates to } \\
\text { increasing productivity and efficiency } \\
\text { of life. }\end{array}$ & $\begin{array}{l}\text { Student 57: "Commuters can use their time to do } \\
\text { something productive such as prepare for a class, } \\
\text { rehearse a talk for a meeting, write emails or even eat } \\
\text { breakfast." }\end{array}$ \\
\hline $\begin{array}{l}\text { Consumer Impact } \\
\text { (Instrumental) }\end{array}$ & $\begin{array}{l}\text { Uncritically emphasizes the consumer } \\
\text { demand model as the driving force of } \\
\text { technological adoption. }\end{array}$ & $\begin{array}{l}\text { Student 77: "If people are comfortable letting cars } \\
\text { drive themselves, then there will be a high demand } \\
\text { for them. However, if they are not comfortable with } \\
\text { the technology yet, then they will not be successful." }\end{array}$ \\
\hline
\end{tabular}


Strained Social Relationships mainly related to students' feelings about how family life would be influenced by the adoption of autonomous vehicles. This includes sentiments about parent/child relationships, how children will grow up, interactions with friends, and increasing social divisions between middle and low income families. For example, students speculated that as people stopped driving their own cars, family members might not see each other as much because children could potentially ride by themselves in AVs to school or sporting events. A few students surmised that the common adolescent activity of driving around with friends might diminish, further limiting social relationships to online activities. References not related to family relationships tended to focus on more general interactions with AVs, for example one student suggested that pedestrians would have to become more "aware and alert" to avoid being hit by AVs. Another student expressed a concern that human drivers would have difficulty "predicting and participating" in a transportation system dominated by AVs. The focus on family relationships can be traced to one of the scenarios students were prompted to discuss focused on how middle income families would influence and be influenced by autonomous vehicle adoption. Interestingly, the other two stakeholders students were asked to focus on (real estate agents and urban planners) generated far less written commentary from students. The possible reasons for this will be discussed further below.

Student references about realtors and urban planners were more common in the Quality of Life and Infrastructure Design themes, but specific statements about these stakeholders didn't dominate these themes like family life did with the Strained Social Relationship theme. Student references about Quality of Life tended to focus on positive notions of having more time and freedom to do other activities besides driving, in one student's words: "more time to do things they love." Another related sub-theme associated with Quality of Life was the potential reduction of traffic congestion. Several students also made general statements about community well-being such as, AVs will make it "more pleasant to live in the city," will "increase standard of living," will "increase the sense of community through public transportation," and will increase "freedom and flexibility to elderly and teenagers unable to drive." A small subset of students honed in on loss of quality of life through too much dependence on technology, vulnerability to hacking, and more loss of privacy.

The Infrastructure Design theme included references to how AVs would require or result in decisions about changes in infrastructure. This theme arose due to how the question was framed. Students were specifically asked to consider the infrastructure changes that would need to happen to accommodate AVs or that would be a consequence of AV adoption. With regards to infrastructure, students often referred to changes in real estate, including housing, parking, and recreational areas. These infrastructural shifts often generated commentary on people changing their behaviors, including migrations to city centers or having more access to recreational opportunities. Students also commented on whether AV transportation systems should be limited to AVs only or mixed human driver/AV systems. Some students believe that AVs will make city life "simpler," while others believe it will complicate life for non-motorized transportation such as bikes.

Student concerns about Public Acceptance of AVs were very common. One of the most common sub-themes centered on a public "hesitant to accept" AVs, which often related to a "fearful public" that would shape concerns about AV safety. Other students wondered "how quickly" the public would adopt AVs. Some sentiments focused on public "trust" or people "feeling comfortable" with the technology. A couple students wrote about the "need for people to demand" AVs for it to be a successful technology. A highly-related theme, Consumer Impact, 
had a very singular, but a relatively common focus. Many students expressed the belief that the success of AVs primarily depended on whether the public demands them as a consumer product. Also of a singular focus, student references in the Economic Efficiency theme reduced the successful adoption of AVs to increased efficiency and productivity of life - common. Student responses related to this theme referred to being able to "get more work done," having more "efficient" commutes, making "city life simpler," or increasing the convenience of moving from place to place.

Human Error generally includes student constructions of human drivers as a source of error. Human driver error had three primary relationships to AVs: 1) the need to replace human drivers with AVs, 2) human drivers as the cause of AV accidents or making AV travel more difficult, and 3) and the less efficient use of infrastructure (e.g., road wouldn't have to be as wide because AVs would need less space). By far the most common sentiment was the reduction of "poor" and "dangerous" drivers. Many students put AVs in opposition or conflict to human drivers.

Research Question 2: Based on previous work ${ }^{3}$, it was established that the classroom activities encourage socio-technical systems thinking. What are the instrumental and non-instrumental constructs that students use to inform their articulation of socio-technical systems?

Of the 189 social, political, and economic student responses (for the 32 students that had their work coded in depth), $53.9 \%$ were instrumental and $46.1 \%$ were non-instrumental, which suggests the exercise did help students see more socio-technical complexity in the adoption of EV/AV technologies. Most of the major themes that students discussed were dominated by instrumental thinking (Public Acceptance, Consumer Impact, Economic Efficiency, Human Error). None of these themes, with the exception of Human Error, were emphasized in the articles chosen for the activities, the activity materials, or lectures. Therefore, it is likely that students were drawing from common over-simplified models of how the social world works and how the public interacts with technology.

We have identified three common constructs among student writings that Science, Technology, and Society and Liberal Engineering Education scholars have previously established as prevalent oversimplified misconceptions about the relationship between society and technology. While the engineering mindsets developed by Donna Riley ${ }^{18}$ provide an excellent framework for understanding barriers to integrating social justice into engineering curriculum, three common constructs outlined below may provide additional specific insight into the ways engineering students construct relationships between technology and society.

Understanding these constructs can help design classroom activities that encourage students to overcome obstacles in achieving diverse non-instrumental thinking that can be transferred to other contexts. The three constructs are: 1) Free market idealism; 2) Technological determinism; 3) Technological neutrality thesis.

Free market idealism refers to constructs that reduce technological development and adoption to rational capitalist economic considerations. We live in a society where design and manufacturability are constrained by how easy and cost-effective they are ${ }^{41}$. This construct also relies on notions of individualism and the agency of individuals as consumers to shape the market, which is only half the picture ${ }^{42}$. What is missing from this construction of technological development are the forces that the private sector uses to shape markets to their benefit through economic power and shaping state and federal legislation in their favor ${ }^{43}$. Student responses that fall under the themes Consumer Impact, Economic Efficiency, and even Public Acceptance are 
adopting this construct. For example, Student 105 wrote "Also, as demand increases, the ranging financial status of people will incentivize vehicles of different prices to appeal to different consumers." A few students do refer to Industry Responses (see Appendix for minor coded themes), but these statements are typically in reference to consumer demand or the adoption of AVs. Students generally don't see industry shaping the market. However, they do make some references to new rules and regulations being necessary to make AVs safe (Governance Appendix).

Technological determinism is a construct guided by models of technological impact where humans (other than technical experts) are reduced to passive agents that adapt to the inevitability of various emerging technologies ${ }^{44,45}$. Technological determinism includes notions of cultural lag, a conceptual framework that attempts to explain why the public rejects, fears, or is slow to adapt to new technology ${ }^{46,47}$. Such a conceptual framework, while popular in social sciences in the mid-20th century, have largely been discounted as complete explanations of technological development ${ }^{45,47}$. Nonetheless, conceptions of technological determinism remain common in popular culture and STEM fields ${ }^{48,49}$. The engineering students in this study extensively adopted these concepts in both the Public Acceptance and Economic Efficiency themes. Public Acceptance figured into student constructions of the public as needing to accept AV technology in order to make the technology successful. For example, Student 89 wrote "In regards to people shaping the development of driverless vehicles, I think companies producing these vehicles need to gain the trust of the people. If people do not trust these products, they will not invest in them." Studies that have explored engineers' imaginaries of the public ${ }^{49}$ show one of the most common constructions of the public as in need of advances in engineering. On the other hand, constructions of the public as engaged in technological development are less common ${ }^{42,50}$. Our study follows a similar pattern, except when students reduced the role of the public to consumers having an impact on AV development.

Technological neutrality thesis is the idea that technology is neutral and its unethical use is a matter of human behavior. A secondary component of this thesis is that problems that arise with technology can often be traced to human error. The argument against this thesis is that humans design their values into technology, which negates any notion of neutrality ${ }^{19,51}$. We argue that imputing human driver error as a primary reason from adopting AVs is a form of the technological neutrality thesis. Reducing the reason to adopt AVs to human error takes the onus of responsibility off the technology, putting the blame on the driver. The history of creating automated driving systems in the United States dates for the purpose of eliminating bad driving dates back to the late 1930s. Over the past 80 years we have seen many failed imaginaries of creating automated systems that will eliminate bad drivers ${ }^{52}$. However, a blame humans first mentality persists ${ }^{53}$, which has its origins in a mindset of technical hubris pervasive among technical experts ${ }^{54}$. For example, this mentality can be seen with the infamous Toyota accelerating vehicle affair in the early 2000s that lead to one of the most expensive recall programs in automotive history from 2009-2011. For a long time Toyota technical experts resisted the notion that the technology was failing and blamed driver error for the problem. Eventually, Toyota conceded that the issue was technological ${ }^{55}$. This mindset was evident among our students (see Human Error theme), exemplified by student 79, "Driverless cars will eliminate the human emotion factor in driving on the road and ultimately protect people from getting into accidents." As the bad human driver narrative is perhaps one of the most common invoked to promote the adoption of $\mathrm{AVs}{ }^{56}$, it is not unreasonable to think that some engineering students could adopt this same mentality, especially as it fits into the neutrality thesis construct 
pervasive in technical culture ${ }^{19,51}$. We should note that not all students adhere to this construct, as student 85 put it, "Driverless cars will shape people's lives as they will have to be aware of their surroundings." This student was thinking about the AV that killed a pedestrian in Arizona, an accident which was also initially blamed on both the pedestrian and vehicle attendant/driver before a technical failure was discovered ${ }^{57}$. Accidents such as this have led to companies such as Jaguar Land Rover to redesign their AVs to help pedestrians understand their intentions ${ }^{58}$.

These constructs, along with the related engineering mindsets outlined by Riley ${ }^{18}$ can make it more difficult for students to adopt modes of non-instrumental thinking. Furthermore, they may have a constraining effect on the diversity of ways student express non-instrumental thinking. Interestingly, students didn't make much reference to common non-instrumental issues with AVs such as privacy, security, over commercialization, and decision making power either in writing or during classroom discussions.

When students did diverge from instrumental thinking, they tended to draw inspiration for non-instrumental thinking directly from the different scenarios used in the EV/AV activity during classroom group work. There is very little evidence of students expanding beyond the complex relationships they discussed for middle income families, realtors, and urban planners, with references to family life by far being the most common expression of non-instrumental thinking. For example, Student 89 commented about the negative impact AVs could have on family bonding: "Driverless vehicles will make life easier for people, but at what cost? If a family uses driverless vehicles, a mother may not drive her children to and from sporting events. If this is the case, the family misses out on quality bonding time. I feel as though this pushes families further away." This student comment demonstrates another trend that was common in student responses. Students tended to voice non-instrumental thinking related to envisioned situations that are commonplace in their lives. Envisioning a parent driving her/his child to a sporting event is probably much easier for college students than envisioning what considerations an urban planner makes when designing a new space. The student above sees the time spent driving with his/her parent as essential to maintaining a close personal bond. Moreover, in class, it was discussed how the parents in the middle-income family would feel about letting their kids ride in an AV alone. For example, Student 65 wrote: "Driverless cars also bring about ethical issues like whether it would be ok to let children ride alone." The classroom discussion about the middle income family had a great impact in students newly formed perceptions of this technology. This is perhaps because it is easier for students to relate to kids and parents, since this is currently such an important part of their lives.

Non-instrumental thinking also appeared in responses related to Quality of Life to a more obscure set of stakeholders. As mentioned in the results of our first research question, more prevalent responses in Quality of Life related to AVs bringing about a more "convenient" lifestyle and the enhanced ability to make use of ride-sharing services and public transportation. In these cases, students invoked a broad definition of a commuter as an important stakeholder. For example, Student 77 wrote: "As the technology become[sic] more reliable, people would be able to work, sleep, or eat while they commute. People would also be more willing to work farther from their homes. They would not have to pay attention to the road and would therefore be more comfortable with a long commute everyday." It is probably easy for engineering students to imagine that soon after they graduate, they will become personal vehicle commuters, since the vast majority of U.S. workers fit that category ${ }^{59}$. 


\section{Limitations}

We would like to recognize the limitations of this study. In any such study where a classroom intervention is introduced and the resulting student work is analyzed, it is difficult to conclude that the intervention changed the way students think and to determine for how long the change will last. Students have many influences in their lives while these classroom activities happen and therefore they are not the only factor shaping their thought processes. Moreover, every student has a different set of values, background, experiences, and mindset, which influences how they may be impacted by classroom activities. Another limitation of this study is that the student work produced here was part of a graded assignment for the course, which often times can generate a feeling that there is a "correct answer" that the instructor is seeking. The answers were limited to 150 words, which can also impact how students choose to report what was discussed in class. The instructors noted that during classroom activities, discussions among students were rich and involved socio-political commentary not captured in written students responses. This suggests that our study may not be capturing the extent that the activity influences student socio-technical systems thinking skills. Future studies should focus on the dialogue among students, which may have implications for how we assess student learning.

\section{Conclusion}

We analyzed student work produced after a classroom activity that focused on the sociotechnical impacts of electric and driverless vehicles. The classroom activity provided the students with background information and informational pieces to the students and allowed extensive classroom discussions on the topics. The readings provided to the students heavily influenced how students responded to how these technologies impact society and how society impacts technology. Student responses ranged over a variety of instrumental and noninstrumental ideas about these technologies and showed that the students rely heavily on materials provided by the instructors. We also observed that activities designed to introduce socio-technical systems thinking are also up against engineering mindsets and popular social constructs such as free market idealism, technological determinism, and the technological neutrality thesis. Moreover, we observed that students were more successful at showing noninstrumental thinking in connection with relatable stakeholders such as family members and commuters. These results may be useful in preparing other socio-technical systems thinking activities that aim to invite students to see past the first-order impacts of the technologies engineers produce.

\section{Future Work}

We use the results of this research to modify and enhance classroom activities that focus on socio-technical thinking. A major element of future work will be to understand how to address over-simplified social constructs such as technological determinism, free market idealism, and the neutrality thesis when conducting socio-technical systems thinking activities. We would also like to determine if the activity described here has any short- and long-term impact on how students understand the societal impact of the engineering technologies they are exposed to as students. As part of the course in which the activity analyzed here took place, a final exam was administered and it included a question that was related to the socio-technical activity discussed in this paper. Future analysis of this data could provide a glimpse into shortterm retention of socio-technical systems thinking demonstrated by the students. Moreover, about 4-6 semesters after the students take this course, they enroll in their capstone final project. 
The project is highly technical and includes a stakeholder analysis. Getting access to the final reports produced by the students and analyzing the data therein would shed light into the longerterm retention of students' socio-technical systems reasoning. 


\section{Appendix}

Table A - Nine minor themes identified through open coding of student social, political, and economic references. Whether a theme has predominantly instrumental, non-instrumental, or mixed references is also noted below.

\begin{tabular}{|c|c|c|}
\hline Minor Themes & Explanation & Student Examples \\
\hline $\begin{array}{l}\text { Things People } \\
\text { Could Do (Mixed) }\end{array}$ & $\begin{array}{l}\text { Mentions of the various things people } \\
\text { could do in driverless vehicles if they } \\
\text { didn't have to drive. }\end{array}$ & $\begin{array}{l}\text { Student 77: "As the technology become more reliable, } \\
\text { people would be able to work, sleep, or eat while they } \\
\text { commute." }\end{array}$ \\
\hline $\begin{array}{l}\text { Vehicle Design } \\
\text { (Instrumental) }\end{array}$ & $\begin{array}{l}\text { How driverless vehicles will be } \\
\text { designed with a focus on safety, } \\
\text { reliability, and efficiency. }\end{array}$ & $\begin{array}{l}\text { Student 63: "[T] he question of manually driven } \\
\text { vehicles interacting with driverless vehicles will cause a } \\
\text { lot of issues because there could be problems in the } \\
\text { technology or design used on driverless vehicles that } \\
\text { could impact these other driver's lives." }\end{array}$ \\
\hline $\begin{array}{l}\text { Skill Loss (non- } \\
\text { instrumental) }\end{array}$ & Refers to the loss of driving skills. & $\begin{array}{l}\text { Student 85: "These cars will also impact us as we will } \\
\text { lose skills such as the basic knowledge of a car and rules } \\
\text { of the road as autonomous cars are equipped to } \\
\text { automatically drive for us." }\end{array}$ \\
\hline $\begin{array}{l}\text { Changing } \\
\text { Transportation } \\
\text { Use Behavior } \\
\text { (mixed) }\end{array}$ & $\begin{array}{l}\text { Focus on how driverless vehicles will } \\
\text { influence our use of public } \\
\text { transportation and travel. }\end{array}$ & $\begin{array}{l}\text { Student 69: "I imagine that driverless vehicles will } \\
\text { increase the amount of ridesharing, which might } \\
\text { decrease the amount of public transportation. Public } \\
\text { transportation struggles in the U.S. as is, as well as other } \\
\text { non-motorized forms of transportation." }\end{array}$ \\
\hline $\begin{array}{l}\text { Industry Response } \\
\text { (mixed) }\end{array}$ & $\begin{array}{l}\text { How the private sector (e.g., } \\
\text { automotive industry) will respond to } \\
\text { consumer demand and the adoption of } \\
\text { driverless vehicles. }\end{array}$ & $\begin{array}{l}\text { Student 61: "consumers will have a large impact on the } \\
\text { driverless car industry. As we discussed in class, it is a } \\
\text { possibility that most of these products are to be sold to } \\
\text { ride-share programs like bus systems and Uber. This } \\
\text { means that driverless car manufacturers will focus their } \\
\text { marketing and products to meet the needs of this group." }\end{array}$ \\
\hline $\begin{array}{l}\text { Economic Growth } \\
\text { (Instrumental) }\end{array}$ & $\begin{array}{l}\text { Statements that refer to driverless } \\
\text { vehicles contributing to economic } \\
\text { growth. }\end{array}$ & $\begin{array}{l}\text { Student 54: "If infrastructure is really changed on a } \\
\text { faster basis, the technology involved will also develop } \\
\text { more quickly. This will also create more jobs in this } \\
\text { industry." }\end{array}$ \\
\hline $\begin{array}{l}\text { Spend Less Money } \\
\text { (Instrumental) }\end{array}$ & $\begin{array}{l}\text { How driverless vehicles will help } \\
\text { people save money. }\end{array}$ & $\begin{array}{l}\text { Student 62: "I believe there will be areas that will need } \\
\text { to expand their infrastructure especially areas that attract } \\
\text { tourist. There will be a larger population of people } \\
\text { commuting to those destinations due to the fact that they } \\
\text { don't have the extra expenses to pay for a hotel room } \\
\text { during the drive as well as the gas expense." }\end{array}$ \\
\hline $\begin{array}{l}\text { Governance } \\
\text { (mixed) }\end{array}$ & $\begin{array}{l}\text { References to new rules, laws, and } \\
\text { regulations associated with the } \\
\text { adoption of driverless vehicles. }\end{array}$ & $\begin{array}{l}\text { Student 55: "The culture is changing as well with a new } \\
\text { vehicle a new set of rules and norms have to be follow } \\
\text { [sic]. Such as new traffic rules or vehicle conditions that } \\
\text { it must meet." }\end{array}$ \\
\hline $\begin{array}{l}\text { Job Loss } \\
\text { (non-instrumental) }\end{array}$ & $\begin{array}{l}\text { Recognition that AV adoption may } \\
\text { lead to job loss. }\end{array}$ & $\begin{array}{l}\text { Student 64: "In a matter of decades, the entire [shipping } \\
\text { industry] occupation of truckers could be displaced and } \\
\text { the infrastructure surrounding the occupation entirely } \\
\text { altered. As a whole, this in not necessarily a good or bad } \\
\text { thing but it will be a drastic change." }\end{array}$ \\
\hline
\end{tabular}




\section{Bibliography}

1. Leydens, J.A., and Lucena, J.C. (2017). Engineering justice: Transforming engineering education and practice (Hoboken, NJ: John Wiley \& Sons).

2. Riley, D. (2011). Engineering thermodynamics and 21st century energy problems: A textbook companion for student engagement. Synthesis Lectures on Engineering 6, 1-97.

3. Andrade, N., and Tomblin, D. (2018). Engineering and Sustainability: The Challenge of Integrating Social and Ethical Issues into a Technical Course. (Salt Lake City, Utah: Paper presented at 2018 ASEE Annual Conference \& Exposition), p.

4. Newberry, B. (2007). Are engineers instrumentalists? Technol. Soc. 29, 107-119.

5. Nieusma, D. (2015). Conducting the instrumentalists: a framework for engineering liberal education. Engineering Studies 7, 159-163.

6. Cech, E.A. (2013). The (mis)framing of social justice: why ideologies of depoliticization and meritocracy hinder engineers' ability to think about social injustices. In Engineering Education for Social Justice, J. Lucena, ed. (Dordrecht: Springer Netherlands), pp. 67-84.

7. Newberry, B. (2004). The dilemma of ethics in engineering education. Sci. Eng. Ethics 10, 343-351.

8. Herkert, J.R. (2005). Ways of thinking about and teaching ethical problem solving: Microethics and macroethics in engineering. Sci. Eng. Ethics 11, 373-385.

9. Riley, D. (2008). Ethics in Context, Ethics in Action: Getting Beyond the Individual Professional in Engineering Ethics Education. (Pittsburgh, PA: Paper presented at 2008 ASEE Annual Conference \& Exposition), p.

10. Cech, E.A. (2014). Culture of disengagement in engineering education? Science, Technology, \& Human Values 39, 42-72.

11. Canney, N.E., Polmear, M., Bielefeldt, A.R., Knight, D., Swan, C., and Simon, E. (2017). Challenges and Opportunities: Faculty Views on the State of Macroethical Education in Engineering. (Columbus, OH: Paper presented at 2017 ASEE Annual Conference \& Exposition), p.

12. Wilson, D., Kim, M.J., Bates, R.A., and Burpee, E. (2014). How Engineering Students View Dilemmas of Macroethics: Links between Depth of Knowledge and Ethical Literacy. (Indianapolis, IN: Paper presented at 2014 ASEE Annual Conference \& Exposition), p.

13. NSF Award Search: Award\#1519453 - IUSE/PFE RED: Developing Changemaking Engineers.

14. Catalano, G., Baillie, C., Riley, C., and Nieusma, D. (2008). Engineering, peace, justice and the Earth: Developing course modules. (Pittsburgh, PA: Paper presented at 2008 ASEE Annual 
Conference \& Exposition), p.

15. Neeley, K.A. (Kathryn A. (2010). Technology and democracy: A sociotechnical systems approach (San Diego, CA: Cognella).

16. Rulifson, G., and Bielefeldt, A. (2017). Motivations to leave engineering: through a lens of social responsibility. Engineering Studies 9, 222-248.

17. Bielefeldt, A. (2017). Disengaging or Disappearing? Losing the most Socially Motivated Students from Engineering? (Columbus, Ohio: Paper presented at 2017 ASEE Annual Conference \& Exposition), p.

18. Riley, D. (2008). Engineering and Social Justice. Synthesis Lectures on Engineers, Technology and Society 3, 1-152.

19. Vermaas, P., Kroes, P., van de Poel, I., Franssen, M., and Houkes, W. (2011). A philosophy of technology: from technical artefacts to sociotechnical systems. Synthesis Lectures on Engineers, Technology and Society 6, 1-134.

20. Allenby, B.R., and Sarewitz, D.R. (2011). The techno-human condition (Cambridge, Mass: MIT Press).

21. Code of Ethics | National Society of Professional Engineers.

22. (2007). The Re-Emergence of Values in ScienceEducation (Rotterdam, The Netherlands: Sense Publishers).

23. Zeidler, D.L. (2016). STEM education: A deficit framework for the twenty first century? A sociocultural socioscientific response. Cult. Stud. Sci. Educ. 11, 11-26.

24. Zeidler, D.L., and Kahn, S. (2014). It's Debatable! Using Socioscientific Issues to Develop Scientific Literacy, K-12 (Arlington, VA: NSTA Press).

25. Lachney, M., and Nieusma, D. (2015). Engineering bait-and-switch: K-12 recruitment strategies meet university curricula and culture. (Seattle, WA: Paper presented at 2015 ASEE Annual Conference \& Exposition), p.

26. Taylor, A.R., Lutz, B.D., Hampton, C., Lee, W.C., and Watford, B.A. (2017). Critical pedagogies and 1st year engineering students' concepts of 'what it means to be an engineer'.' (Columbus, OH: Paper presented at 2017 ASEE Annual Conference \& Exposition), p.

27. Seron, C., and Silbey, S.S. (2009). The dialectic between expert knowledge and professional discretion: accreditation, social control and the limits of instrumental logic. Engineering Studies $1,101-127$.

28. Riley, D. (2013). Power. Systems. Engineering. Traveling lines of resistance in academic institutions. In Engineering Education for Social Justice: Critical Explorations and Opportunities (Philosophy of Engineering and Technology Book 10), J. Lucena, ed. (Netherlands: Dordrecht: Springer), pp. 41-63. 
29. Hacker, S. (1989). Pleasure, power, and technology: Some tales of gender, engineering, and the cooperative workplace (Boston: Unwin Hyman).

30. Philip, T.M., Gupta, A., Elby, A., and Turpen, C. (2017). Why ideology matters for learning: A case of ideological convergence in an engineering ethics classroom discussion on drone warfare. Journal of the Learning Sciences 1-41.

31. Nussbaum, M. (2007). Human Rights and Human Capabilities. Harv Hum Rights J 20, 2124.

32. Fung, B. (2017). As Hurricane Irma bore down, Tesla gave some Florida drivers more battery juice. Here's why that's a big deal. The Washington Post.

33. Wade, L. (2016). Tesla's Electric Cars Aren’t as Green as You Might Think. Wired.

34. Driving Electric NYC - Are Electric Cars Good for Society?

35. Randall, T. (2016). Here's How Electric Cars Will Cause the Next Oil Crisis.

36. (2016). The Lifecycle Impact of Electric Vehicles.

37. Ashley, J. (2017). The driverless car revolution isn't just about technology - it's about society too. The Guardian.

38. Eldredge, B. (2016). 5 ways driverless cars will change our roads and highways. Curbed.

39. Saldaña, J. (2013). The coding manual for qualitative researchers (Los Angeles: SAGE).

40. Strauss, A.L., and Corbin, J.M. (1990). Basics of qualitative research: Grounded theory procedures and techniques (Newbury Park, Calif: Sage Publications).

41. McGinn, R. (2018). The ethical engineer: Contemporary concepts and cases (Princeton, NJ: Princeton University Press).

42. Canney, N.E. (2018). Engineers" imaginaries of "the public": Dominant themes from interviews with engineering students, faculty, professionals. (Salt Lake City, UT: Paper presented at 2018 ASEE Annual Conference \& Exposition), p.

43. Frickel, S., and Moore, K. (2005). The New Political Sociology of Science (Madison, WI: University of Wisconsin Press).

44. Bijker, W.E., Hughes, T.P., and Pinch, T. (1987). The Social construction of technological systems: New directions in the sociology and history of technology (Cambridge, Mass: MIT Press).

45. Smith, M.R., and Marx, L. (1994). Does technology drive history? The dilemma of technological determinism (Cambridge, Mass: MIT Press).

46. Hess, D.J. (2015). Publics as threats? Integrating science and technology studies and social movement studies. Sci Cult (Lond) 24, 69-82.

47. Volti, R. (2014). Society and technological change (New York: Worth Publishers). 
48. Wisnioski, M. (2015). What's the use? History and engineering education research. J. Eng. Educ.

49. Jasanoff, S., and Kim, S.-H. (2009). Containing the atom: sociotechnical imaginaries and nuclear power in the United States and South Korea. Minerva 47, 119-146.

50. Lambrinidou, Y., and Canney, N.E. (2017). Engineers' imaginaries of "the public": Content analysis of foundational professional documents. (Columbus, OH: Paper presented at 2017 ASEE Annual Conference \& Exposition), p.

51. Trevelyan, J. (2010). Reconstructing engineering from practice. Engineering Studies 2, 175195.

52. Wetmore, J. (2003). Driving the dream - the history and motivations behind 60 years of automated highway systems in America. Automotive History Review 4-19.

53. Norton, P. (2015). Four paradigms: traffic safety in the twentieth-century United States. Technol. Cult. 56, 319-334.

54. Jasanoff, S. (2003). Technologies of Humility: Citizen Participation in Governing Science. Minerva 223-244.

55. Vlasic, B., and Apuzzo, Ma. (2014). Toyota Is Fined $\$ 1.2$ Billion for Concealing Safety Defects - The New York Times. The New York Times.

56. JafariNaimi, N. (2018). Our Bodies in the Trolley's Path, or Why Self-driving Cars Must *Not* Be Programmed to Kill. Science, Technology, \& Human Values 43, 302-323.

57. Wakabayashi, D. (2018). Uber's Self-Driving Cars Were Struggling Before Arizona Crash The New York Times. The New York Times.

58. Krok, A. (2019). Jaguar Land Rover uses light to tell pedestrians where self-driving cars are going - Roadshow. Road Show by CNET.

59. America's commuting choices: 5 major takeaways from 2016 census data. 